\title{
Sensorless Control of Surface-Mount Permanent-Magnet Synchronous Motors Based on a Nonlinear Observer
}

\author{
Junggi Lee, Student Member, IEEE, Jinseok Hong, Student Member, IEEE, Kwanghee Nam, Member, IEEE, \\ Romeo Ortega, Fellow, IEEE, Laurent Praly, and Alessandro Astolfi, Fellow, IEEE
}

\begin{abstract}
A nonlinear observer for surface-mount permanentmagnet synchronous motors (SPMSMs) was recently proposed by Ortega et al. (LSS, Gif-sur-Yvette Cedex, France, LSS Internal Rep., Jan. 2009). The nonlinear observer generates the position estimate $\hat{\theta}$ via the estimates of $\sin \theta$ and $\cos \theta$. In contrast to Luenberger-type observers, it does not require speed information, thus eliminating the complexity associated with speed estimation errors. Further, it is simple to implement. In this study, the nonlinear observer performance is verified experimentally. To obtain speed estimates from the position information, a proportionalintegral (PI) tracking controller speed estimator was utilized. The results are good with and without loads, above $10 \mathrm{r} / \mathrm{min}$.
\end{abstract}

Index Terms-Motor drives, nonlinear estimation, observers, permanent magnet machines, permanent magnet motors.

\section{INTRODUCTION}

$\mathbf{P}$ OSITION information is required for field orientation control of permanent-magnet synchronous motors (PMSMs). In some applications, installing position sensors is troublesome. For instance, in some vacuum pumps, it is not possible to extend the motor shaft out of the motor housing due to sealing problems. In crane and elevator applications, the distance between the motor and inverter is so large that sensor signal attenuation and noise interference are high. In some household equipments such as refrigerators and air conditioners cost constraints stymie the use of speed sensors. The aforementioned problems motivated the development of sensorless algorithms for PMSMs, for which numerous works have been published.

Manuscript received January 20, 2009; revised March 30, 2009 and May 15, 2009. Current version published February 12, 2010. Recommended for publication by Associate Editor J. O. Ojo.

J. Lee, J. Hong, and K. Nam are with the Department of Electrical Engineering, Pohang University of Science and Technology (POSTECH) University, Pohang 790-784, Republic of Korea (e-mail: baabu@postech.ac.kr; jinsuk00@postech.ac.kr; kwnam@postech.ac.kr).

R. Ortega is with the Laboratoire des Signaux et Systèmes, Supelec, 91192 Gif-sur-Yvette Cedex, France (e-mail: ortega@1ss.supelec.fr).

L. Praly is with the Centre Automatique et Systèmes, Ecole de Mines des de Paris, 77305 Fontainebleau, France (e-mail: praly@ensmp.fr).

A. Astolfi is with the Department of Electrical and Electronic Engineering, Imperial College London, London SW7 2AZ, U.K., and also with the Dipartimento di Informatica, Sistemi e Produzione (DISP), University of Rome "Tor Vergata," 00133 Rome, Italy (e-mail: a.astolfi@ic.ac.uk).

Color versions of one or more of the figures in this paper are available online at http://ieeexplore.iee.org.

Digital Object Identifier 10.1109/TPEL.2009.2025276
Sensorless techniques for PMSMs are broadly classified into three types: motion electromotive force (EMF), inductance, and flux linkage [2]. Matsui [3] pioneered the area of sensorless controls for PMSMs with position- and speed-update algorithms based on current errors, which originated from coordinate misalignments. Ogasawara and Akagi [14] derived angle estimates by utilizing the dependence of inductance on the rotor position when the rotor has saliency. Tomita et al. [4] introduced a disturbance observer for an EMF-based estimator. Corley and Lorenz [5] proposed a sensorless control that operated at zero speed with a high-frequency current injection and a heterodyne filtering technique. Aihara et al. [6] combined a signal injection technique with a back EMF-based position estimation method. Nahid-Mobarakeh et al. [8] studied the influence of measurement errors and inverter irregularities on the performance of the sensorless control. Xu and Rahman [10], Liu et al. [12], and Chen et al. [7] used adaptive sliding-mode observers, and Bolognani et al. [11] applied the extended Kalman filter and proposed guidelines for choosing noise covariance matrices. Bianchi et al. [24] compared two signal injection methods for zero-speed rotor position detection.

It is widely recognized that back-EMF-based methods perform well for middle- and high-speed applications. However, the major drawback is that they behave poorly at standstill and in the low-speed region. Further, they are sensitive to inherent motor torque ripple and noises. However, with high-frequency signal injection methods, full-torque zero-speed operation is feasible.

Solsona et al. [20] used a nonlinear observer along with nonlinear coordinate transformation for surface-mount permanentmagnet synchronous motor (SPMSM) and load dynamics. However, their state contains speed variable and the transformed equations are complex. Jansson et al. [21] utilized $d$-axis current in proportion to $q$-axis current to reduce the effect of stator resistance variation, and showed stable performances in starting and speed reversal.

Recently, Ortega et al. [17] established some theoretical properties of a nonlinear observer for SPMSM. Instrumental to our development was the use of a new state variable representation of the motor dynamics [18]. The proposed observer used the flux linkage as the new state variable and the speed dependence was eliminated. The main interest of the observer of [17] is its simplicity, which makes it a suitable candidate for practical implementation. In this paper, a sensorless controller with the nonlinear observer is constructed, and its practical usefulness is demonstrated. 


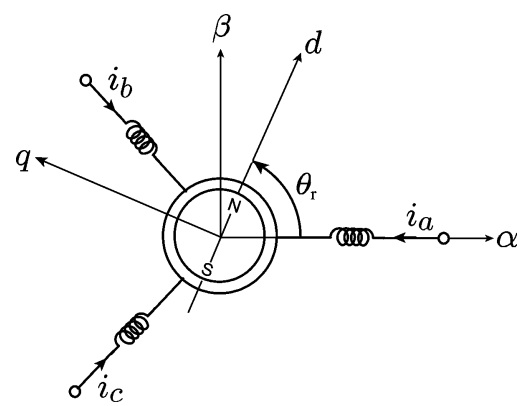

Fig. 1. Schematic diagram of the PMSM.

\section{NONLINEAR POSITION OBSERVER FOR SPMSM}

Fig. 1 shows a schematic diagram of a PMSM with a sinusoidal flux distribution, where $d-q$ axes denote a synchronous reference frame and $\alpha-\beta$ axes denote the stationary reference frame. Note that $d$-axis is rotated from $\alpha$-axis by angle $\theta_{r}$.

In the stationary $\alpha-\beta$ frame, the SPMSM dynamics are given by

$$
\begin{aligned}
L \dot{i}_{\alpha \beta} & =-R_{s} i_{\alpha \beta}+\omega \psi_{m}\left[\begin{array}{c}
\sin \theta \\
-\cos \theta
\end{array}\right]+v_{\alpha \beta} \\
T_{e} & =\frac{3 P}{4} \psi_{m}\left(i_{\alpha} \cos \theta-i_{\beta} \sin \theta\right)
\end{aligned}
$$

where $i_{\alpha \beta}=\left[i_{\alpha}, i_{\beta}\right]^{T}$ is stator current, $v_{\alpha \beta}=\left[v_{\alpha}, v_{\beta}\right]^{T}$ is the motor terminal voltage, $\theta=(P / 2) \theta_{r}, \omega=(P / 2)(d / d t)(\theta), R_{s}$ is the stator resistance, $L$ is the stator inductance, $\psi_{m}$ is the permanent magnet flux linkage, $T_{e}$ is the electromagnetic toque, and $P$ is the number of poles. Suppose that $r_{s}$ and $l_{s}$ are the phase resistance and inductance, respectively. Then, it follows that $R_{s}=(3 / 2) r_{s}$ and $L=(3 / 2) l_{s}$. Note also that since the motor under consideration is an SPMSM, $d$ - and $q$-axis inductances are the same. As a result, $L$ is not dependent on the angle $\theta$.

It is assumed that only current $i_{\alpha \beta}$ is available for measurement and voltage $v_{\alpha \beta}$ is known. On the other hand, due to the absence of position/speed sensors, it is assumed that angle $\theta$ and speed $\omega$ are unknown.

\section{A. Position Observer Construction}

In this study, we utilize the nonlinear position observer for SPMSM proposed by Ortega et al. [17]. In view of its simplicity, and for ease of reference, we repeat its construction here. First, a new state variable is defined as

$$
x=L i_{\alpha \beta}+\psi_{m}\left[\begin{array}{c}
\cos \theta \\
\sin \theta
\end{array}\right] .
$$

Let

$$
y \equiv-R_{s} i_{\alpha \beta}+v_{\alpha \beta} .
$$

Note that $y$ does not include any unknown term, thereby is available for measurement. Then, it follows from (1), (3), and (4) that

$$
\dot{x}=L \dot{i}_{\alpha \beta}-\omega \psi_{m}\left[\begin{array}{c}
\sin \theta \\
-\cos \theta
\end{array}\right]=y .
$$

The current dynamics is then reduced to the simplest form $\dot{x}=$ $y$.

To construct the nonlinear observer, define a vector function $\eta: \mathbb{R}^{2} \rightarrow \mathbb{R}^{2}$ as

$$
\eta(x)=x-L i_{\alpha \beta} .
$$

In view of (3), its Euclidean norm is equal to

$$
\|\eta(x)\|^{2}=\psi_{m}^{2} .
$$

Consider the nonlinear observer

$$
\dot{\hat{x}}=y+\frac{\gamma}{2} \eta(\hat{x})\left[\psi_{m}^{2}-\|\eta(\hat{x})\|^{2}\right]
$$

where $\hat{x} \in \mathbb{R}^{2}$ is the observer state variable and $\gamma>0$ is an observer gain. Note that $\psi_{m}^{2}-\|\eta(\hat{x})\|^{2}$ is the distance squared between $\eta(\hat{x})$ and the circle of radius $\psi_{m}$.

From observation of $x$, it is possible to reconstruct $\theta$ in the following way. First, note that from (3), we get

$$
\frac{1}{\psi_{m}}\left(x-L i_{\alpha \beta}\right)=\left[\begin{array}{c}
\cos \theta \\
\sin \theta
\end{array}\right] .
$$

Hence, defining

$$
\left[\begin{array}{c}
\cos \hat{\theta} \\
\sin \hat{\theta}
\end{array}\right] \equiv \frac{1}{\psi_{m}}\left(\hat{x}-L i_{\alpha \beta}\right)
$$

we get

$$
\hat{\theta}=\tan ^{-1}\left(\frac{\hat{x}_{2}-L i_{\beta}}{\hat{x}_{1}-L i_{\alpha}}\right)
$$

where $\hat{\theta}$ is the estimate of $\theta$. Note that even when the denominator is near to zero, arctangent function is not sensitive.

Define the observation error by $\tilde{x} \equiv \hat{x}-x$. Then, the error dynamics directly follows from (3)-(8) such that

$$
\begin{aligned}
\dot{\tilde{x}} & =-\gamma a(\tilde{x}, t)\left\{\tilde{x}+\psi_{m}\left[\begin{array}{l}
\cos \theta(t) \\
\sin \theta(t)
\end{array}\right]\right\} \\
a(\tilde{x}, t) & \equiv \frac{1}{2}\|\tilde{x}\|^{2}+\psi_{m}\left[\tilde{x}_{1} \cos \theta(t)+\tilde{x}_{2} \sin \theta(t)\right] .
\end{aligned}
$$

It is shown in [17] that (10) satisfies the following stability properties.

Pl (Global stability): For arbitrary speeds, the disk

$$
\left\{\tilde{x} \in \mathbb{R}^{2} \mid\|\tilde{x}\| \leq 2 \psi_{m}\right\}
$$

is globally attractive. This means that all trajectories of (10) will converge to this disk.

P2 (Local stability under persistent excitation): The zero equilibrium of (10) is exponentially stable if there exists constants $T, \Delta>0$ such that

$$
\frac{1}{T} \int_{t}^{t+T} \omega^{2}(s) d s \geq \Delta .
$$

P3 (Constant nonzero speed): If the speed is constant and satisfies

$$
|\omega|>\frac{1}{4} \gamma \psi_{m}^{2}
$$




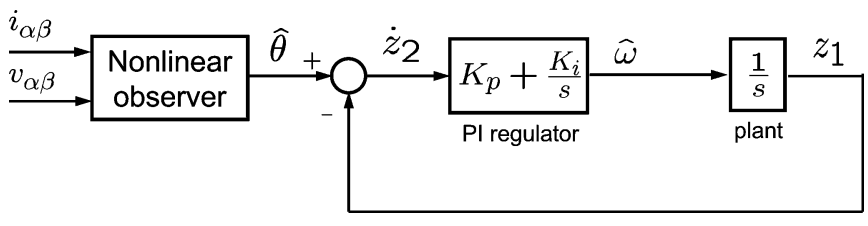

Fig. 2. Speed observer construction utilizing position estimate, $\hat{\theta}$.

then the origin is the unique equilibrium of (10) and it is globally asymptotically stable. ${ }^{1}$

Remark 1: It is also proven in [17] that at zero speed, the vector $x$ is not observable; hence, it is not possible to reconstruct the position with an observer; therefore, other techniques, e.g., signal injection, should be tried.

Remark 2: It should be noted that the observer (8) does not require speed information, which is a strong advantage. Normally, Luenberger-type observers cannot be constructed without knowing $\omega$. For example, see [8] and [9].

Remark 3: A similar nonlinear observer was utilized in [20]. However, the state variable, $z$ does not contain any current variable. In contrast, it contains speed $\omega$. Thus, the model includes the mechanical dynamics, so that it depends on the load characteristics. Correspondingly, the full description is quite complex. However, in this paper, only the motor model is dealt. The state variable, $x$ does not contain $\omega$. Hence, the original motor dynamics (2) are transformed succinctly into a simple form (5). If there is no angle error, then $\psi_{m}^{2}=\|\eta(\hat{x})\|^{2}$. The difference, $\psi_{m}^{2}-\|\eta(\hat{x})\|^{2}$ is used as the driving term that forces the error to vanish.

\section{B. Speed Observer}

To construct a speed controller or to compensate the crosscoupling voltages, $\omega L i_{d}$ and $\omega L i_{q}$, it is necessary to estimate the speed. However, it is not desirable to obtain a speed estimate through numerical differentiation of the position estimates. Instead, we utilize a tracking-controller-type speed estimator of the form [19]

$$
\begin{aligned}
\dot{z}_{1} & =K_{p}\left(\hat{\theta}-z_{1}\right)+K_{i} z_{2} \\
\dot{z}_{2} & =\hat{\theta}-z_{1} \\
\hat{\omega} & =K_{p}\left(\hat{\theta}-z_{1}\right)+K_{i} z_{2}
\end{aligned}
$$

where $K_{p}$ and $K_{i}$ are proportional and integral gains, respectively. The speed estimator block diagram is shown in Fig. 2. The loop bandwidth can be made wide by selecting proper PI gains, $K_{p}$ and $K_{i}$. Then, $z_{1}$ tracks $\hat{\theta}$, if $\hat{\theta}$ is not changing fast compared with the loop bandwidth. Since $z_{1} \approx \hat{\theta}$, the node value prior to the integral block, $1 / s$ implies a speed estimate $\hat{\omega}$. Application study of the similar PLL-type speed estimator was shown in [22] and [23].

\footnotetext{
${ }^{1}$ Note the presence of the free adaptation gain $\gamma$ on the lower bound.
}

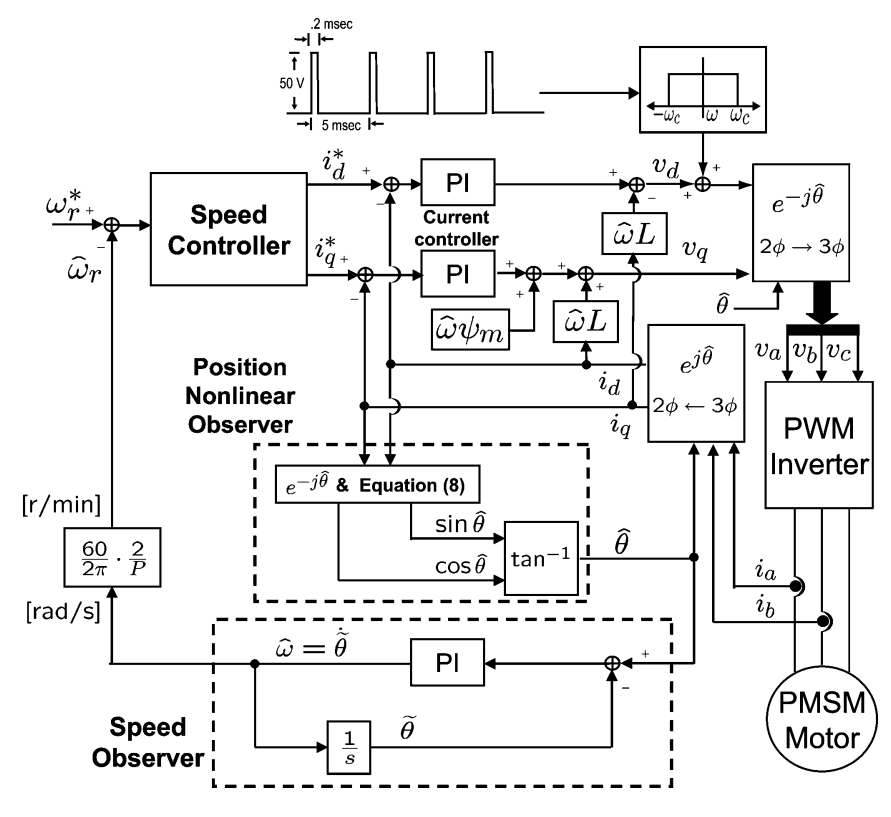

Fig. 3. Overall sensorless control block diagram with the nonlinear observer and the speed estimator.

\section{Sensorless Control}

The dynamic model of SPMSM in the synchronous frame is given by

$$
\begin{aligned}
& L \dot{i}_{d}^{e}=-R_{s} i_{d}^{e}+\omega L i_{q}^{e}+v_{d}^{e} \\
& L \dot{i}_{q}^{e}=-R_{s} i_{q}^{e}-\omega L i_{d}^{e}-\omega \psi_{m}+v_{q}^{e}
\end{aligned}
$$

where superscript "e" signifies a variable in the synchronous frame. The sensorless control block for an SPMSM that includes the nonlinear observer is shown in Fig. 3. The nonlinear observer outputs angle estimate $\hat{\theta}$ based on which the field orientation control is established. A conventional PI controller is utilized for $d$ - and $q$-axis current control along with the decoupling and the back-EMF compensation. The speed controller utilizes $\hat{\omega}$ that comes out from the speed estimator.

Jansson et al. [21] pointed that injection of $d$-axis current enhanced the robustness of the sensorless system against $R_{s}$ variation. They applied $d$-axis current in proportion to $q$-axis current. However, we inject $d$-axis current pulses in a low-frequency region. To generate such current pulses, we apply a voltage pulse train, as shown in Fig. 3. In this experiment, the pulse frequency is $200 \mathrm{~Hz}$, the peak level is $50 \mathrm{~V}$, and the pulse duty is $0.2 \mathrm{~ms}$. Note that no $d$-axis current is injected if $|\omega|>100 \mathrm{r} / \mathrm{min}$.

\section{Simulation AND EXPERIMENTAL REsults}

Simulation was performed with the MATLAB Simulink using the motor parameters listed in Table I. Fig. 4(a) shows the speed command $\omega_{r}^{*}$ and the shaft speed $\omega_{r}$. In the speed control block, a torque limit and a field weakening were set up. In addition to the inertial load caused by speed changes, extra load torques were applied, as shown in Fig. 4(b). The speed response looks satisfactory even under the load torque step change. Fig. 4(c) and (d) shows estimates, $\sin \hat{\theta}, \cos \hat{\theta}$, and $\hat{\theta}$ in an expanded time 
TABLE 1

PARAMETERS OF SPMSMS FOR SIMULATION AND EXPERIMENTS

\begin{tabular}{c|c|c}
\hline \hline Parameters & $\begin{array}{c}\text { Simulation } \\
\text { Motor }\end{array}$ & $\begin{array}{c}\text { Test } \\
\text { Motor }\end{array}$ \\
\hline IUnit] & 240 & 200 \\
Rated output power [kW] & 40 & 0.3 \\
Rated torque $[\mathrm{Nm}]$ & 180 & 3.0 \\
Rated speed $[\mathrm{r} / \mathrm{min}]$ & 2200 & 1000 \\
Rated phase current $[\mathrm{A}]$ & 216 & 3.0 \\
Number of pole $(P)$ & 6 & 8 \\
Rotor flux $\left(\psi_{m}\right)[\mathrm{Wb}]$ & 0.146 & 0.11 \\
Switching frequency $[\mathrm{kHz}]$ & 8 & 8 \\
Stator inductance $(L)[\mathrm{mH}]$ & 0.655 & 1.14 \\
Stator resistance $\left(R_{s}\right)[\Omega]$ & 0.065 & 0.675 \\
Observer gain $(\gamma)$ & 2500 & 8000 \\
\hline \hline
\end{tabular}

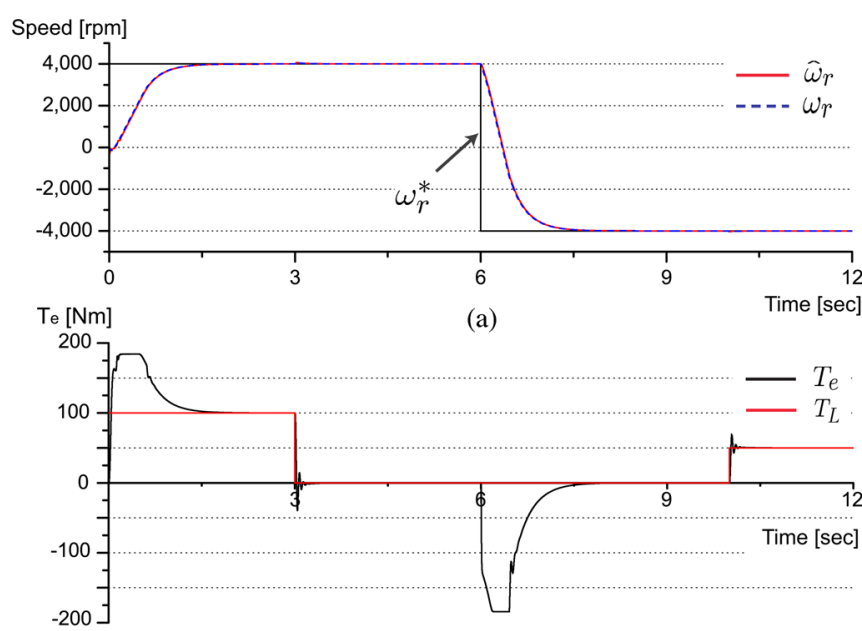

(b)

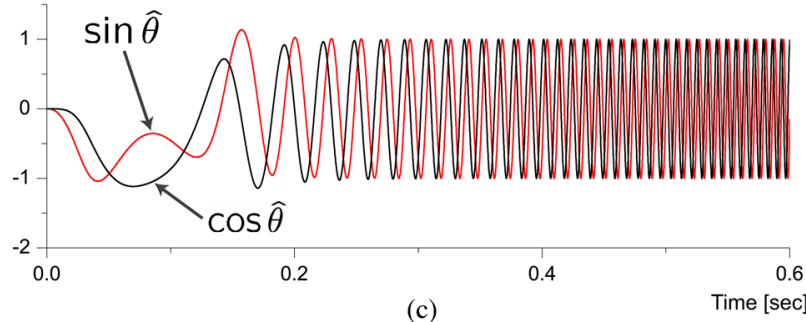

[rad/s]

(c)

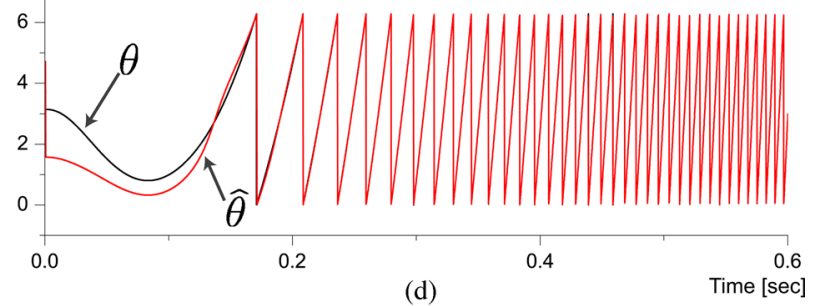

(d)

Fig. 4. Simulation results of (a) real speed and the estimated speed. (b) Load torque and the torque response. (c) Estimated trigonometrical functions, $\sin \hat{\theta}$ and $\cos \hat{\theta}$. (d) Real position and its estimates.

scale. A good tracking performance was shown after a transient period.

Experiments was performed with a dynamo test bench that was made from two SPMSMs. The shafts of the two motors were connected via a coupler, as shown in Fig. 5(b). All the nonlinear observer and control algorithms were implemented in

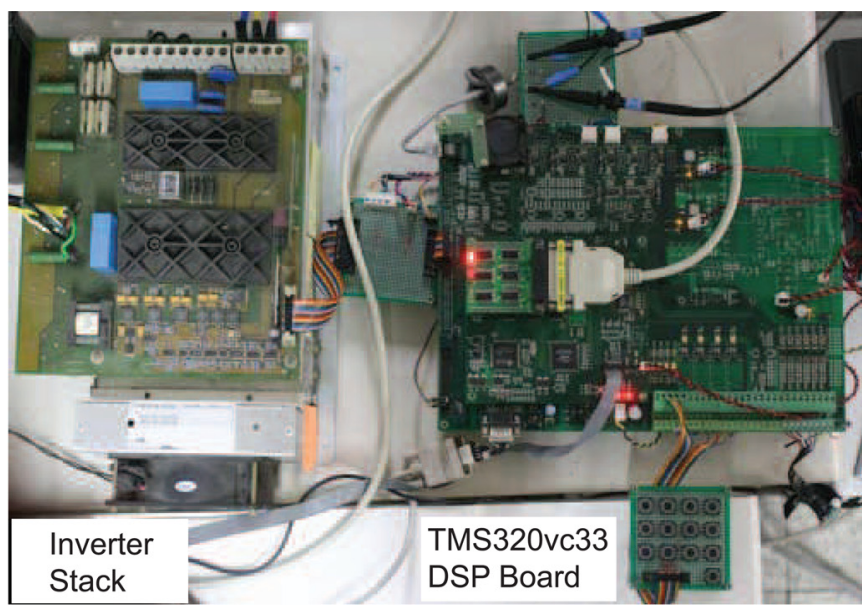

(a)

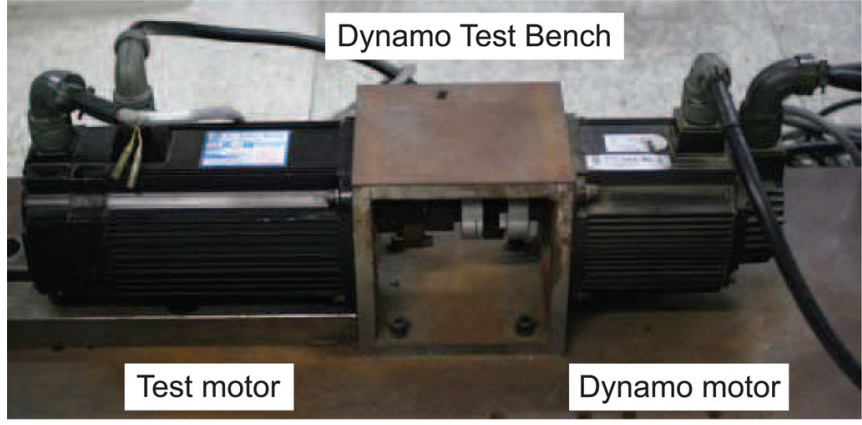

(b)

Fig. 5. Photos of the experiment setup. (a) Inverter for the test motor. (b) Dynamo test bench.

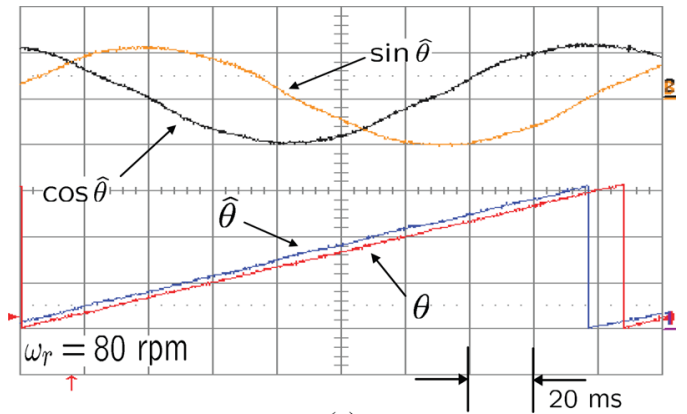

(a)

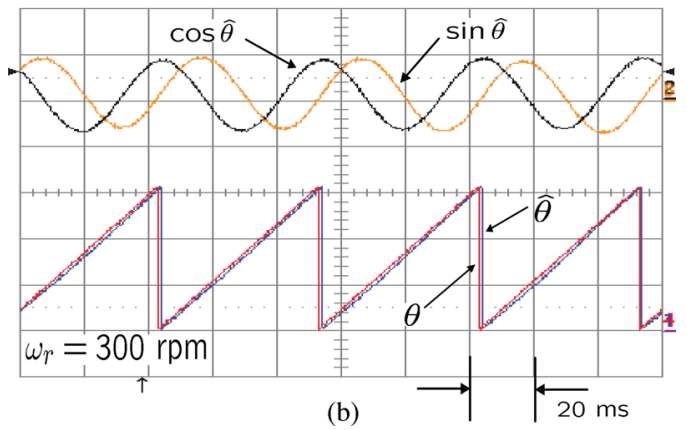

Fig. 6. Comparison between the real and the estimated position data under no-load condition at (a) $80 \mathrm{r} / \mathrm{min}$ and (b) $300 \mathrm{r} / \mathrm{min}$. 


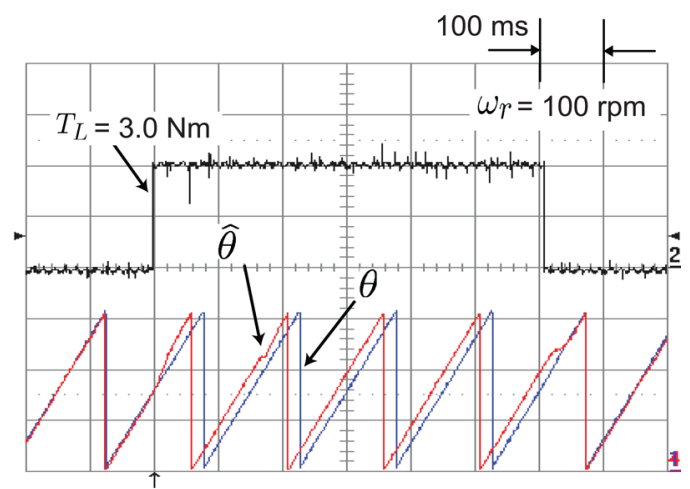

(a)

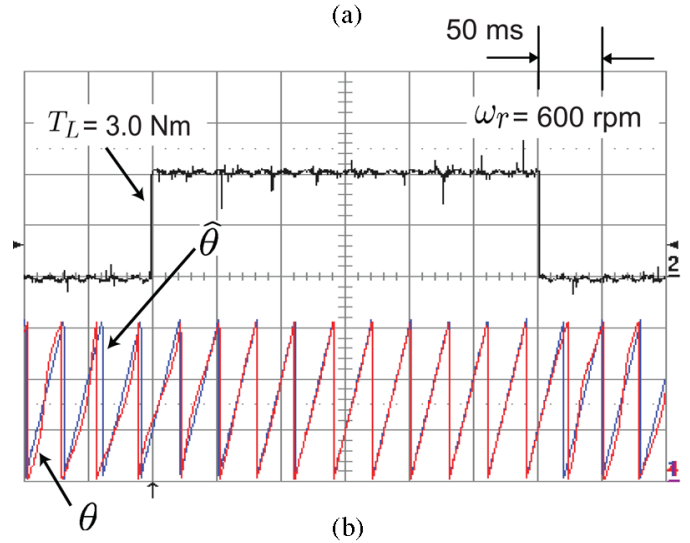

(b)

Fig. 7. Comparison between the real and the estimated position data under a full step load at (a) $100 \mathrm{r} / \mathrm{min}$ and (b) $600 \mathrm{r} / \mathrm{min}$.

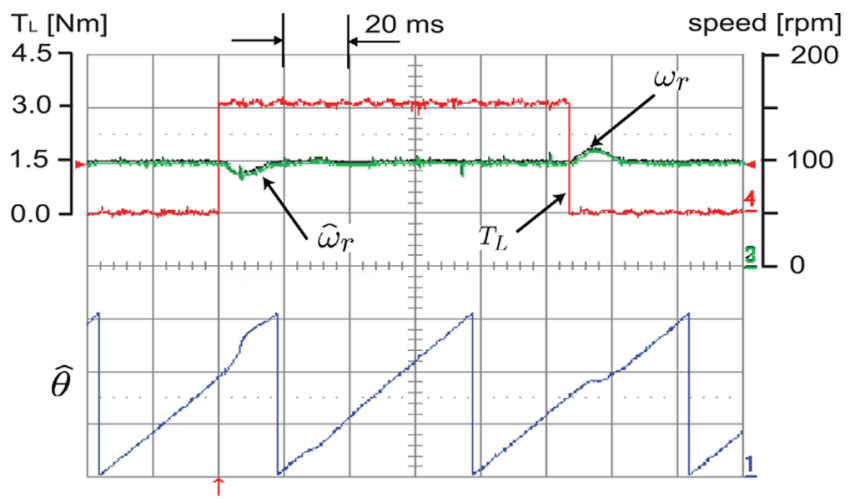

(a)

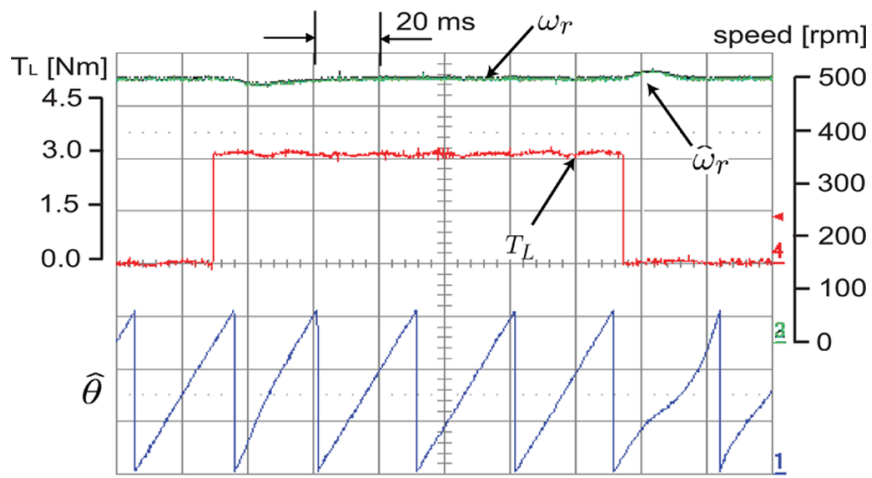

(b)

Fig. 8. Speed responses with a full step load at (a) $100 \mathrm{r} / \mathrm{min}$ and (b) $500 \mathrm{r} / \mathrm{min}$.

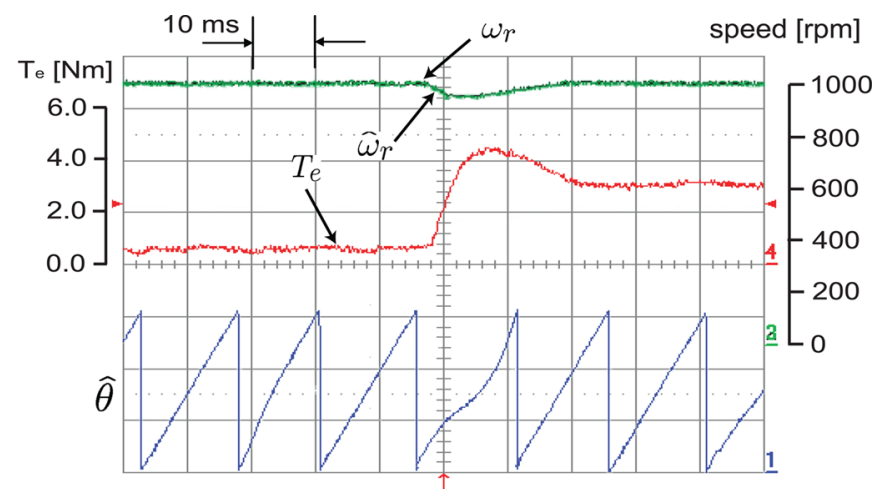

(a)

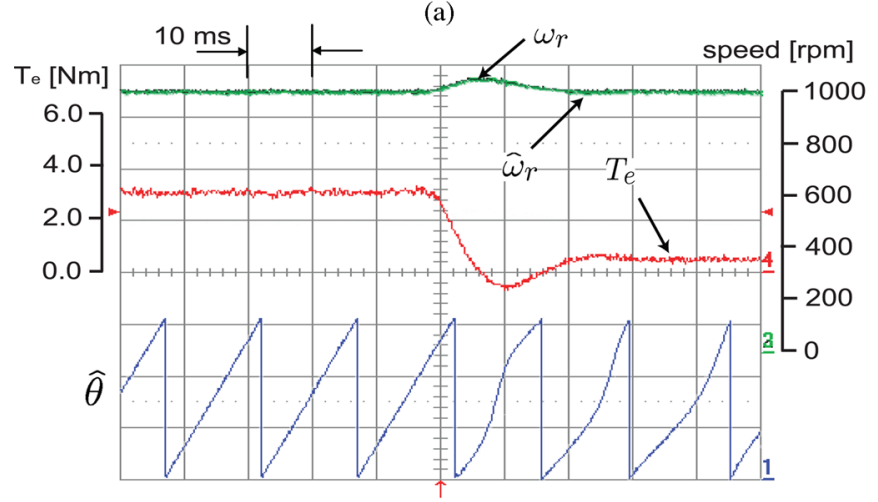

(b)

Fig. 9. Speed and the corresponding torque responses at $1000 \mathrm{r} / \mathrm{min}$ when a full-load torque is (a) applied and (b) removed.

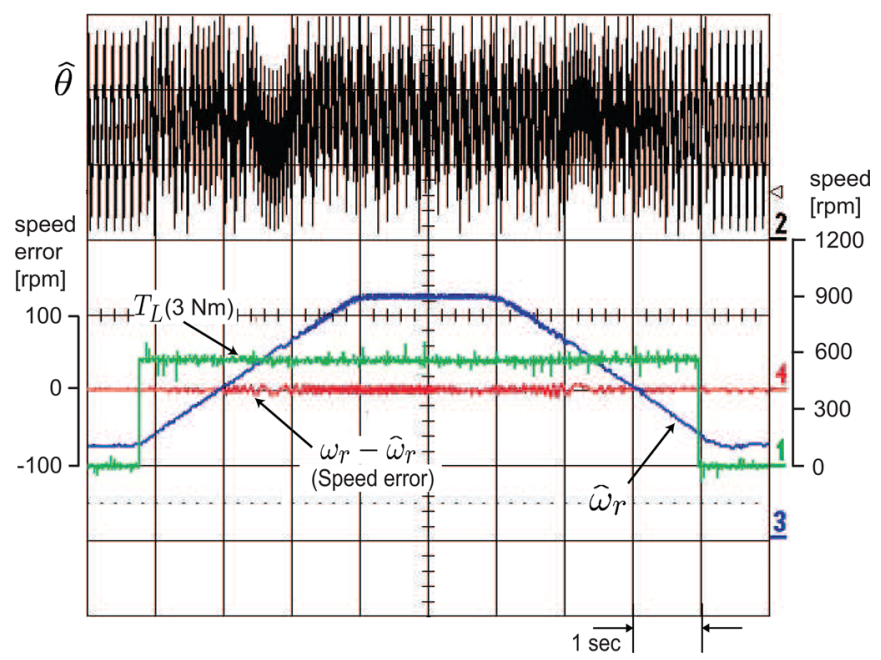

Fig. 10. Speed control response with a step full-load torque.

a TMS320vc33 DSP board shown in Fig. 5(a). The pulsewidth modulation (PWM) switching frequency was set to be $8 \mathrm{kHz}$ and the dead time $2 \mu \mathrm{s}$. The dead time was compensated, and voltage command values were used for $v_{\alpha \beta}$ in the nonlinear observer (8). The current control algorithm was carried out every $125 \mu \mathrm{s}$, and the speed control loop was activated every $1.25 \mathrm{~ms}$.

Fig. 6 shows $\sin \hat{\theta}, \cos \hat{\theta}$, and $\hat{\theta}$, along with real position $\theta$ measured by a 6000 pulses per revolution encoder under no load when (a) $\omega_{r}=80 \mathrm{r} / \mathrm{min}$ and (b) $300 \mathrm{r} / \mathrm{min}$, respectively. 


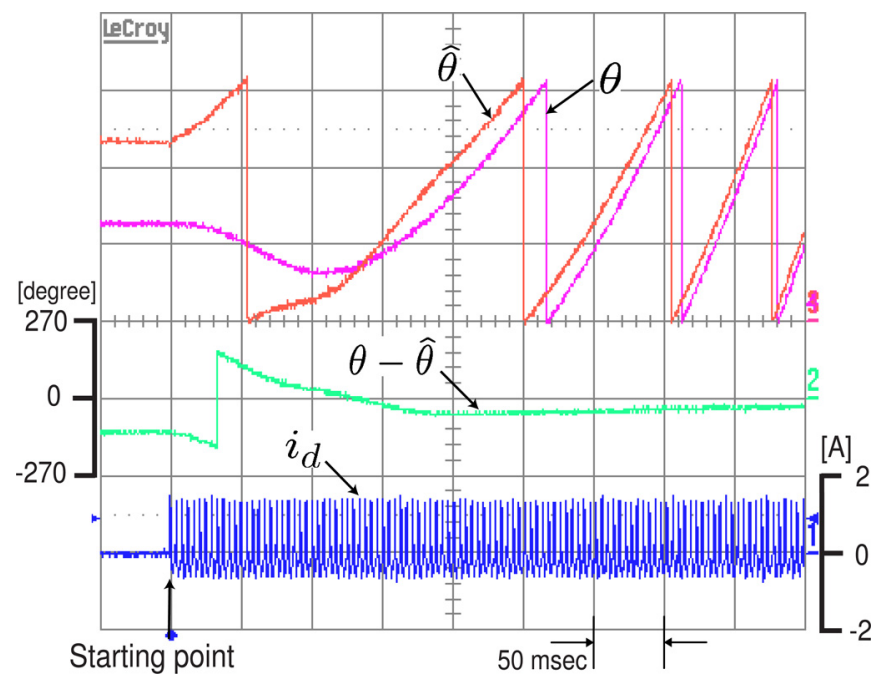

Fig. 11. Experimental result at start-up.

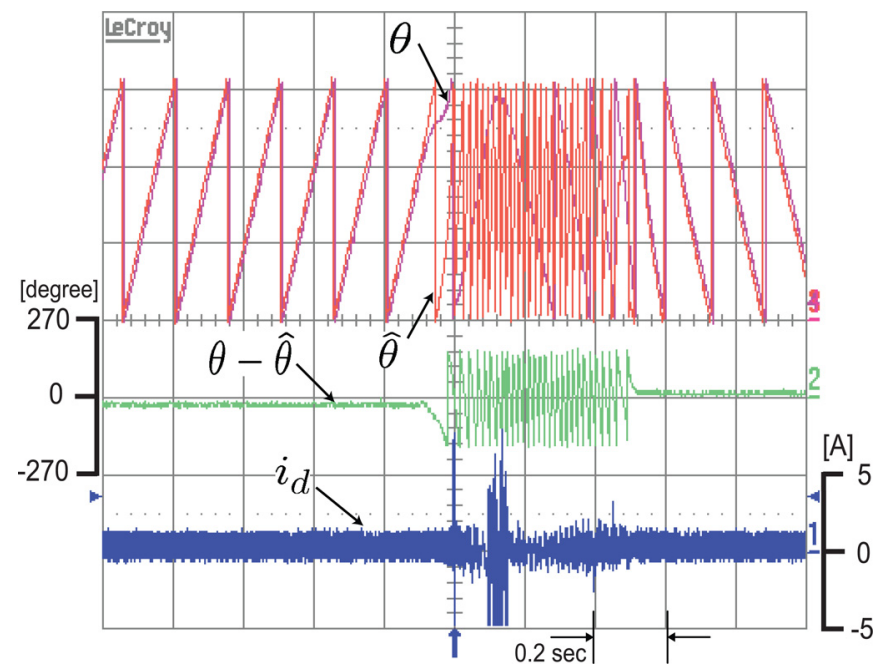

Fig. 12. Experimental result during speed reversal from 100 to $-100 \mathrm{r} / \mathrm{min}$.

Trigonometrical functions as a simple observer output are also shown in Fig. 6. Note that the position errors at $300 \mathrm{r} / \mathrm{min}$ are smaller than those at $80 \mathrm{r} / \mathrm{min}$. Fig. 7(a) and (b) show behaviors of the position estimates when full step loads were applied when $\omega_{r}=100$ and $600 \mathrm{r} / \mathrm{min}$, respectively. Also the steady state position errors at a higher speed are smaller.

Fig. 8(a) and (b) shows the changes of the speed estimates when the full step load is applied and removed at $\omega_{r}=100$ and 500 r/min, respectively. Fig. 9(a) and (b) shows the responses of the speed estimates and the corresponding torque at the time of full-load loading and removal when $\omega_{r}=1000$ r/min, respectively. Fig. 10 shows a macroscopic view of the behavior of speed and angle estimates when the speed changes from $\omega_{r}=100$ to $900 \mathrm{r} / \mathrm{min}$ with a full-load step.

As predicted by the theory, the performance of the system was strongly degraded when the speed approached zero. Fig. 11 shows the plot of angle estimation error and $d$-axis current when the motor is starting. In the starting, no extra starting algorithm was utilized. Fig. 12 shows the angle estimation error during a

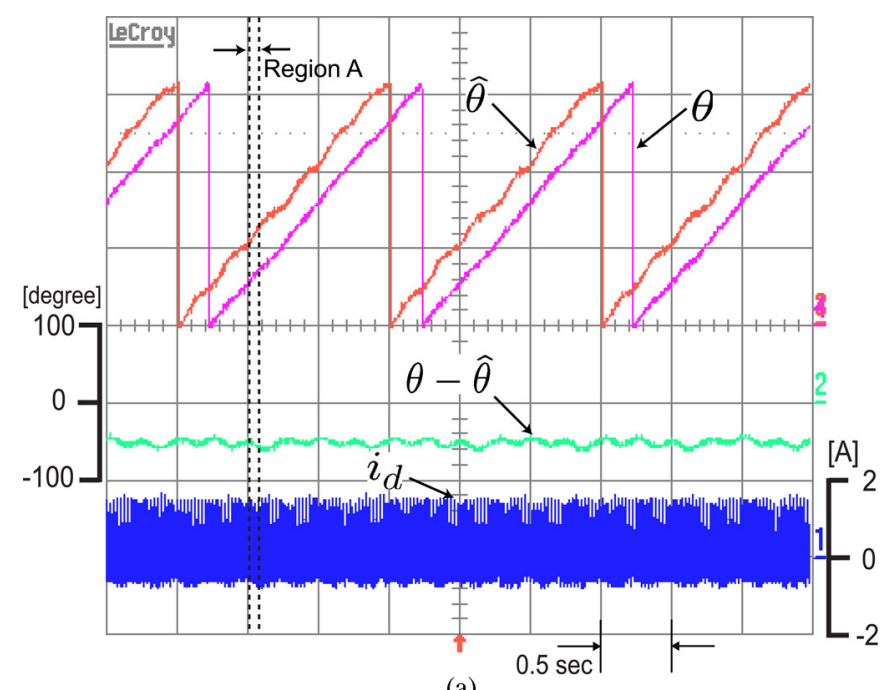

(a)

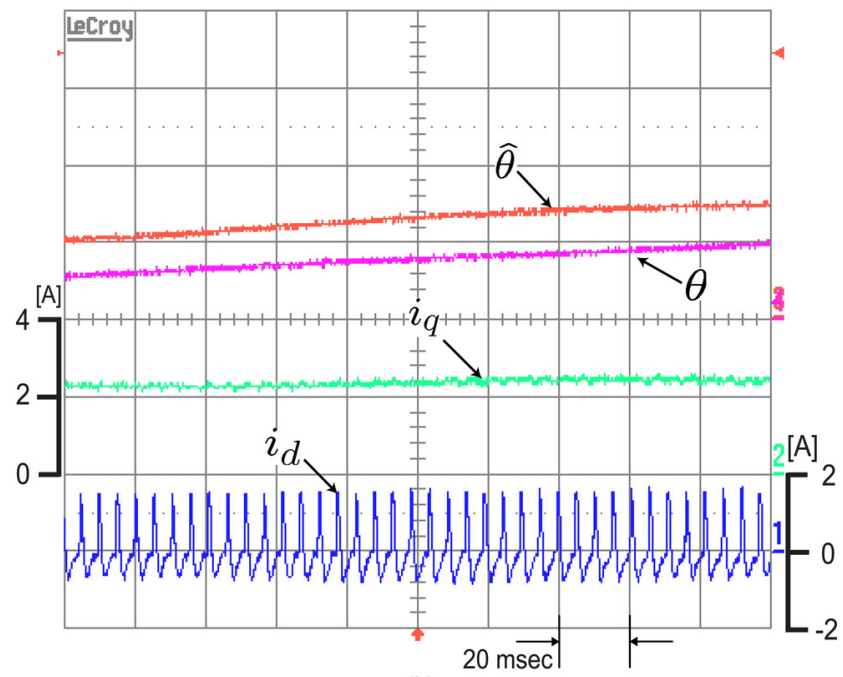

(b)

Fig. 13. (a) Experimental results under half load $(1.5 \mathrm{~N} \cdot \mathrm{m})$ at $10 \mathrm{r} / \mathrm{min}$. (b) Expanded plot of the region A with $i_{q}$ in (a).

speed reversal (from 100 to $-100 \mathrm{r} / \mathrm{min}$ ). Note that as the speed approaches to zero, the angle error oscillates to a great extent. However, as the speed builds up, the angle error vanishes. Note also that the envelope of $i_{d}$ oscillates around zero speed, since the inaccuracy in the reference frame angle is also amplified. Fig. 13 shows a stable performance at $10 \mathrm{r} / \mathrm{min}(0.01 \mathrm{p} . u$. $)$ with a $1.5 \mathrm{~N} \cdot \mathrm{m}(0.5$ p.u.) load. Fig. 13(b) is an expanded plot of real and estimated angles shown in Fig. 13(a). Note that $d$-axis current has a shape of pulse train and that a nonzero $q$-axis current (2.2 A) is flowing for torque production.

\section{CONCLUDING REMARKS}

The proposed nonlinear observer is simple and performs well in practical sensorless applications. In general, the speed $\omega$ appears as a parameter in the observer, which is a major obstacle in the estimation of angle $\theta$. However, the proposed observer does not require speed information. The speed is estimated separately using a PLL-type PI tracking controller. The controller is robust 
with the addition of $d$-axis current in the low-speed region. Experiments showed stable performances at $10 \mathrm{r} / \mathrm{min}(0.01 \mathrm{p.u}$. with 0.5 p.u. load, as well as at the rated speed $(1000 \mathrm{r} / \mathrm{min})$ with a full rated torque.

\section{ACKNOWLEDGMENT}

The authors appreciate anonymous reviewers for their constructive comments that led to the improvements of this paper.

\section{REFERENCES}

[1] P. C. Krause, Analysis of Electric Machinery. New York: McGraw-Hill, 1986.

[2] P. P. Acarnley and J. F. Watson, "Review of position-sensorless operation of brushless permanent-magnet machines," IEEE Trans. Ind. Electron. vol. 53, no. 2, pp. 352-362, Apr. 2006.

[3] N. Matsui, "Sensorless PM brushless DC motor drives," IEEE Trans. Ind. Electron., vol. 43, no. 2, pp. 300-308, Apr. 1996.

[4] M. Tomita, T. Senjyu, S. Doki, and S. Okuma, "New sensorless controls for brushless dc motors using disturbance observers and adaptive velocity estimations," IEEE Trans. Ind. Electron., vol. 45, no. 2, pp. 274-282, Apr. 1998.

[5] M. J. Corley and R. D. Lorenz, "Rotor position and velocity estimation for a salient-pole permanent magnet synchronous machine at standstill and high speeds," IEEE Trans. Ind. Appl., vol. 34, no. 4, pp. 784-789, Jul./Aug. 1998.

[6] T. Aihara, A. Toba, T. Yanase, A. Mashimo, and K. Endo, "Sensorless torque control of salient-pole synchronous motor at zero-speed operation," IEEE Trans. Power Electron., vol. 14, no. 1, pp. 202-208, Jan. 1999.

[7] Z. Chen, M. Tomita, S. Doki, and S. Okuma, "New adaptive sliding observers for position- and velocity-sensorless controls of brushless DC motors," IEEE Trans. Ind. Electron., vol. 47, no. 3, pp. 582-591, Jun. 2000.

[8] B. Nahid-Mobarakeh, F. Meibody-Tabar, and F. M. Sargos, "Back EMF estimation-based sensorless control of PMSM: Robustness with respect to measurement errors and inverter irregularities," IEEE Trans. Ind. Appl., vol. 43, no. 2, pp. 485-494, Mar./Apr. 2007

[9] J. Solsona, M. I. Valla, and C. Muravchik, "On speed and rotor position estimation in permanent-magnet AC drives," IEEE Trans. Ind. Electron., vol. 47 , no. 5, pp. $1176-1180$, Oct. 2000.

[10] Z. Xu and M. F. Rahman, "An adaptive sliding stator flux observer for a direct-torque-controlled IPM synchronous motor drive," IEEE Trans. Ind. Electron., vol. 54, no. 5, pp. 2398-2406, Oct. 2007.

[11] S. Bolognani, L. Tubiana, and M. Zigliotto, "Extended Kalman filter tuning in sensorless PMSM drives," IEEE Trans. Ind. Appl., vol. 39, no. 6, pp. 1741-1747, Nov./Dec. 2003.

[12] Y. Liu, Z. Q. Zhu, and D. Howe, "Instantaneous torque estimation in sensorless direct-torque-controlled brushless DC motors," IEEE Trans. Ind. Appl., vol. 42, no. 5, pp. 1275-1283, Sep./Oct. 2006.

[13] J. L. Shi, T. H. Liu, and Y. C. Chang, "Adaptive controller design for sensorless IPMSM drive system with a maximum torque control," Proc. Inst. Electr. Eng. Electr. Power Appl., vol. 153, no. 6, pp. 823-833, Nov. 2006.

[14] S. Ogasawara and H. Akagi, "Implementation and position control performance of a position-sensorless IPM motor drive system based on magnetic saliency," IEEE Trans. Ind. Appl., vol. 34, no. 4, pp. 806-812, Jul./Aug. 1998.

[15] M. Schroedl, "Sensorless control of AC machines at low speed and standstill based on the "INFORM" method," in Proc. IEEE Ind. Appl. Soc. Апnи. Meeting, Oct. 1996, pp. 270-277.

[16] G. Zhu, A. Kaddouri, L. A. Dessaint, and O. Akhrif, "A nonlinear state observer for the sensorless control of a permanent-magnet AC machine," IEEE Trans. Ind. Electron., vol. 48, no. 6, pp. 1098-1108, Dec. 2001.

[17] R. Ortega, L. Praly, A. Astolfi, J. Lee, and K. Nam, "Two provably stable observers for rotor position and speed of permanent magnet synchronous motors," LSS, Gif-sur-Yvette Cedex, France, Int. Report LSS, Jan. 2009.

[18] F. Poulain, L. Praly, and R. Ortega, "An observer for PMSM with application to sensorless control," ENSMP, Fontainebleau, France, Int. Report ENSMP, Apr. 2008.
[19] S. Morimoto, K. Kawamoto, M. Sanada, and Y. Takeda, "Sensorless control strategy for salient-pole PMSM based on extended EMF in rotating reference frame," IEEE Trans. Ind. Appl., vol. 38, no. 4, pp. 1054-1061, Jul./Aug. 2002.

[20] J. Solsona, M. I. Valla, and C. Muravchik, "A nonlinear reduced order observer for permanent magnet synchronous motors," IEEE Trans. Ind. Electron., vol. 43, no. 4, pp. 492-497, Aug. 1996.

[21] M. Jansson, L. Harnefors, O. Wallmark, and M. Leksell, "Synchronization at startup and stable rotation reversal of sensorless nonsalient PMSM drives," IEEE Trans. Ind. Electron., vol. 53, no. 2, pp. 379-387, Apr. 2006.

[22] O. Wallmark and L. Harnefors, "Sensorless control of sailent PMSM drives in the transient region," IEEE Trans. Ind. Electron., vol. 53, no. 4, pp. 1179-1187, Apr. 2006.

[23] L. Harnefors and H. Nee, "A general algorithm for speed and position estimation of AC motors," IEEE Trans. Ind. Electron., vol. 47, no. 1, pp. 77-83, Feb. 2000.

[24] N. Bianchi, S. Bolognani, J.-H. Jang, and S.-K. Sul, "Comparison of PM motor structures and sensorless control techniques for zero-speed rotor position detection," IEEE Trans. Power Electron., vol. 22, no. 6, pp. 2466-2475, Nov. 2007.

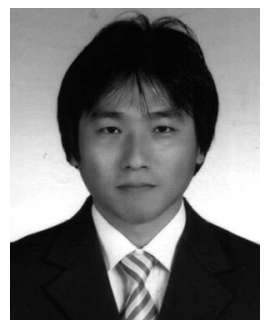

Junggi Lee (S'02) was born in Jeonju, Korea, in 1975. He received the B.S. degree in control and instrumentation engineering from Chonbuk National University, Jeonju, Korea, in 2002, and the M.S. degree in electrical engineering in 2004 from Pohang University of Science and Technology (POSTECH), Pohang, Korea, where he is currently working toward the Ph.D. degree.

His current research interests include design, analysis, and control of power electronic systems, ac motor drive, electric vehicle, and fuel cell systems.

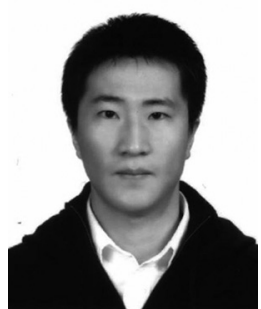

Jinseok Hong ( $\mathrm{S}^{\prime} 08$ ) was born in Incheon, Korea, in 1982. He received the B.S. degree in electrical engineering and mechanical engineering from Hongik University, Seoul, Korea, in 2007, and the M.S. degree in electrical engineering in 2009 from Pohang University of Science and Technology (POSTECH), Pohang, Korea, where he is currently working toward the Ph.D. degree.

His current research interests include design, analysis and control of power electronic systems, ac motor drives, and electric vehicle.

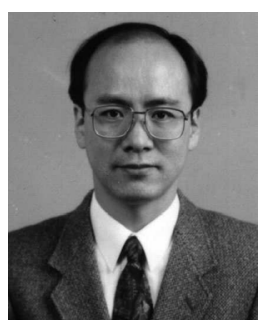

Kwanghee Nam (S'83-M'86) was born in Seoul, Korea, in 1956. He received the B.S. degree in chemical technology and the M.S. degree in control and instrumentation engineering from Seoul National University, Seoul, Korea, in 1980 and 1982, respectively, and the M.S. degree in mathematics and the Ph.D. degree in electrical engineering from the University of Texas, Austin, in 1986

From 1998 to 2000, he was the Director of the Information Research Laboratories and the Dean of the Graduate School of Information Technology, Pohang University of Science and Technology (POSTECH), Pohang, Korea, where he is currently a Professor in the Department of Electrical Engineering. His current research interests include ac motor control, power converters, electric vehicles, computer networks, fuel cell systems, and nonlinear system analysis.

Prof. Nam received the IEEE TRANSACTIONS ON INDUSTRIAL ELECTRONICS Best Paper Award in 2000. 


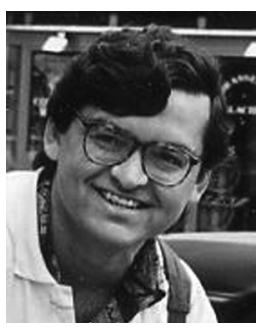

Romeo Ortega (F'99) was born in Mexico. He received the B.Sc. degree in electrical and mechanical engineering from the National University of Mexico, Mexico, Mexico, in 1974, the M.Eng. degree from the Polytechnical Institute of Leningrad, Leningrad, Russia, in 1978, and the Docteur D`Etat degree from the Politechnical Institute of Grenoble, Grenoble, France, in 1984.

He joined the National University of Mexico, where he worked until 1989. He was a Visiting Professor at the University of Illinois in 1987-1988, and at the McGill University in 1991-1992, and a Fellow of the Japan Society for Promotion of Science in 1990-1991. He has been a member of the French National Researcher Council (CNRS) since June 1992. He is currently with the Laboratoire de Signaux et Systemes, Supelec, Gif-sur-Yvette, France. His current research interests include the fields of nonlinear and adaptive control, with special emphasis on applications. He is an Associate Editor of Systems and Control Letters and International Journal of Adaptive Control and Signal Processing.

Dr. Ortega was the Chairman in several International Federation of Accountants (IFAC) and IEEE Committees and Editorial Boards. He is currently the Chair of the Automatica Paper Prize Award Committee (2009-2012) and is an Editor-at-Large of the IEEE TRANSACTIONS ON AUTOMATIC CONTROL.

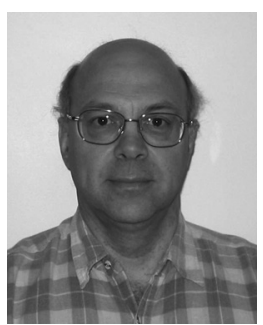

Laurent Praly graduated from École Nationale Supérieure des Mines de Paris, Paris, France, in 1976. After working in industry for three years, in 1980, he joined the Centre Automatique et Systèmes at École des Mines de Paris. From July 1984 to June 1985, he spent a sabbatical year as a Visiting Assistant Professor in the Department of Electrical and Computer Engineering, University of Illinois, UrbanaChampaign. Since 1985, he has been with the Centre Automatique et Systèmes, where he was the Director for two years. His current research interests include feedback stabilization of controlled dynamical systems under various aspectslinear and nonlinear, dynamic, output, under constraints, with parametric or dynamic uncertainty, disturbance attenuation, or rejection. He is engaged in the theoretical aspect with many academic publications and the practical aspect with applications in power systems, mechanical systems, aerodynamical, and space vehicles.

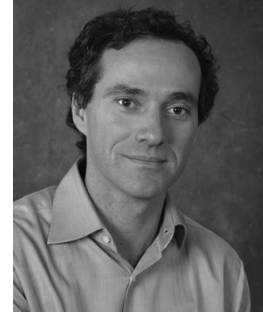

Alessandro Astolfi (SM'02-F'09) was born in Rome, Italy, in 1967. He received the Laurea degree in electrical engineering (cum laude) from the University of Rome, Rome, in 1991, the M.Sc. degree in information theory and the Ph.D. degree (with Medal of Honor) with a thesis on discontinuous stabilization of nonholonomic systems from ETH-Zurich, Zurich, Switzerland, in 1992 and 1995, respectively, and the $\mathrm{Ph} . \mathrm{D}$. degree (nonlinear robust control) from the University of Rome "La Sapienza," Rome, Italy, in 1996.

Since 1996, he has been with the Department of Electrical and Electronic Engineering, Imperial College London, London, U.K., where he is currently Professor in nonlinear control theory. From 1998 to 2003, he was also an Associate Professor at the Department of Electronics and Information, Politecnico of Milano, Milan, Italy. Since 2005, he has been a Professor with the Dipartimento di Informatica, Sistemi e Produzione (DISP), University of Rome "Tor Vergata," Rome, Italy. He has been Visiting Lecturer in nonlinear control in several universities. His current research interests include mathematical control theory and control applications, with special emphasis for the problems of discontinuous stabilization, robust stabilization, robust and adaptive control, observer design, and model reduction. He is the author of more than 90 journal papers, 20 book chapters, and more than 200 papers in refereed conference proceedings. He is the author of the monograph "Nonlinear and Adaptive Control with Applications" (Springer-Verlag).

$\mathrm{He}$ is an Associate Editor of Systems and Control Letters, Automatica, TRANSACTIONS ON AUTOMATIC CONTROL, the International Journal of Control, the European Journal of Control, the Journal of the Franklin Institute, and the International Journal of Adaptive Control and Signal Processing. He is also a member of the International Program Committee (IPC) of various international conferences. 